\title{
Strengthening of concrete beams by CFRP: Experimental study and finite element analysis
}

\author{
Ghernouti $\mathrm{Y}^{*}, 1$, Rabehi $\mathrm{B}^{1}$, Benhamna $\mathrm{A}^{2}$ and Hadj Mostefa $\mathrm{A}^{3}$
}

\author{
1 Research Unit: Materials, Processes and Environment, University M’Hamed Bougara of Boumerdes. Algeria. \\ 2 Laboratory LPQ3M, University of Mascara, Algeria. \\ 3 Laboratory of Civil Engineering, University of Sidi Bel Abbes. Algeria. \\ * Corresponding Author: y ghernouti@yahoo.fr
}

\begin{abstract}
This work presents an experimental study on the mechanical behavior of structural concrete reinforced by carbon fiber reinforced polymer (CFRP). The main purpose of this study is to test the applicability of this method of reinforcement in the beams to improve the behavior of concrete: strength and ductility. An experimental characterization of mechanical behavior by tensile test by three point bending is achieved, namely, the reinforcement of the lower part of the beam $(15 \times 15 \times 75) \mathrm{cm}^{3}$ with composite material, Based on the ANSYS simulation, a model was developed to validate the different results obtained experimentally. The experimental results show that the reinforced concrete offered a great improvement in strength and ductility; in effect an influence directly on the failure mode is observed and then read by the value of strength and ultimate deformation. The tensile bending of beams reinforced by CFRP is more than $295 \%$ in comparison with that of nonreinforced beams. The gain maximum of ductility is $247 \%$. The experimental results have been compared with the theoretical models, a good correlation was obtained.
\end{abstract}

Key words: Strengthening, CFRP, ductility, finite element analyses FEA, simulation.

\section{Introduction}

For several years, the rehabilitation and strengthening of reinforced concrete structures are becoming increasingly important in construction. There are several factors that may be necessary to strengthen or repair a structure: corrosion of steel reinforcement, concrete cracking, changes in assignment that imposes new burdens, development standards accidents (chock against an element of the structure), damaged caused by an earthquake, the extending of the life of a structure, etc....

Therefore, researchers have attempted to find alternative materials that would solve this problem, and have turned to non-metallic materials, especially fiber reinforced polymer (FRP). They have many qualities: a considerably low weight, a high tensile strength, flexibility, enabling them to take many shapes, no corrosion, good durability, and low thickness. Composite materials based on FRP have been used for confinement of concrete since the early 1980s, although the use of plastic tubes (PVC), filled with concrete, began in the late 1970s. In recent years, significant work is reported on the confinement of concrete columns with FRPs. These studies are mainly conducted on the compressive strength and stress-strain behavior of concrete reinforced by FRP.

The use of FRP materials in flexural strengthening of reinforced concrete shallow beams has been investigated quite extensively in the past (Yoon, 2000; Uji, 1992; Al-Sulaimani, 1994; Malvar, 1995; Sato, 1996; Malek, 1998; Chaallal, 1998; Triantafillou, 1998). The results of these investigations have demonstrated the effectiveness of different forms of FRP systems, namely sheet, strip and wrap to achieve the desired effects.

Numerous experimental and analytical investigators directed their attention to study the fracture of plain concrete. On the contrary, much less attention, both on experimental and analytical levels, has been given to study the fracture behavior of reinforced concrete. Yannopoulos (1989) experimentally tested tensile concrete specimens $76 \mathrm{~mm}$ in diameter and 
$1000 \mathrm{~mm}$ long with one $16 \mathrm{~mm}$ deformed steel bar in the center of the specimen. Azad et al. (1989), Azad and Baluch (1990) and Ashmawi et al. (1993) conducted experimental tests on three-point bend reinforced concrete beams. Baluch et al. (1992) tested one beam size with two different reinforcing ratios. Yehia (2003) tested 18 specimens with three different beam size and six different reinforcing ratios. Sorour (2004) tested 45 specimens with five different reinforcing ratios and same specimen size under displacement controlled testing. Sumarac et al. (2003) investigated the fracture of reinforced concrete beams subjected to three-point bending analytically (using fracture mechanics), numerically (using finite elements), and experimentally (using load controlled testing). Wahab and Yehia (2006) tested 9 flanged and 3 rectangular sections. On the analytical level, few investigations have been directed to apply elastic fracture mechanics approach to reinforced concrete elements. Salah and El-Adawy (1975) used an energy balance cracking criterion along with finite element analysis in order to predict the cracking moment of reinforced concrete beams. Carpinteri et al. (1981) proposed a fracture mechanics model for bending of reinforced concrete beams assuming a linear elastic material model for concrete and a linear elastic- plastic model for steel. The effect of reinforcing steel bars was simulated by a closing force whose magnitude was determined by a compatibility condition. Ashmawi et al. (1993) and Baluch et al. (1992) modified this model to include the nonlinear behavior of concrete under compression. Bosco et al. (1990) investigated the minimum reinforcement in concrete beams. A similar analysis based on the fictitious crack model has been proposed by Grestel et al. (1992).

This article concerns in particular, the study of flexural behavior resulting from the reinforcement effect provided by composite materials made from carbon fiber on concrete beams. The gains in strength and deformation of the concrete are evaluated and analyzed. This up-to-date topic is of major interest in the field of construction and materials, taking into account criteria of sustainability, resilience, and vulnerability in the design of elements of reinforced concrete structures.

\section{Experimental program}

\subsection{Materials}

All the cylinders of dimensions $160 \times 320 \mathrm{~mm}$ were carried out with only one composition of aggregates, comprising a crushed coarse sand supplied by the Tizi quarry (Mascara, Algeria) and two types of gravel (3/8) and (8/15). Cement of the type CEM II 32.5 was supplied by the cement factory of Chlef (Algeria) with a class of $43 \mathrm{MPa}$. The concrete composition was determined according to the method of Dreux-Gorisse (Dreux, 1998).

\subsection{FRP material}

In this study, the composite material being used is a carbon fiber fabric (SIKA WRAP HEX 230C), from the company SIKA in rolls of $3500 \mathrm{~mm}$ length and $300 \mathrm{~mm}$ wide with a thickness of $1.2 \mathrm{~mm}$ with an unidirectional fabric embedded in a matrix of black epoxy (Figure 1(a)).

The resin used for bonding composite materials on the concrete surface is a resin called SIKA DUR-330 (Figure 1(b)).

The mechanical properties of FRP material and the resin are represented in the Table1.

Table 1. Mechanical properties of FRP materials and resin (Youcef, 2010; Ghernouti, 2012).

\begin{tabular}{|c|c|c|}
\hline & CFRP & Resin \\
\hline \hline Tensile strength (MPa) & $345-690$ & $>30$ at two days and $20^{\circ} \mathrm{C}$ \\
\hline Elastic modulus in tension (GPa) & $>165$ & 4.5 at seven days and $23^{\circ} \mathrm{C}$ \\
\hline Ultimate elongation in tensile (\%) & 1.7 & $/$ \\
\hline Compressive stress (MPa) & $/$ & $>55$ at two days and $20^{\circ} \mathrm{C}$ \\
\hline
\end{tabular}




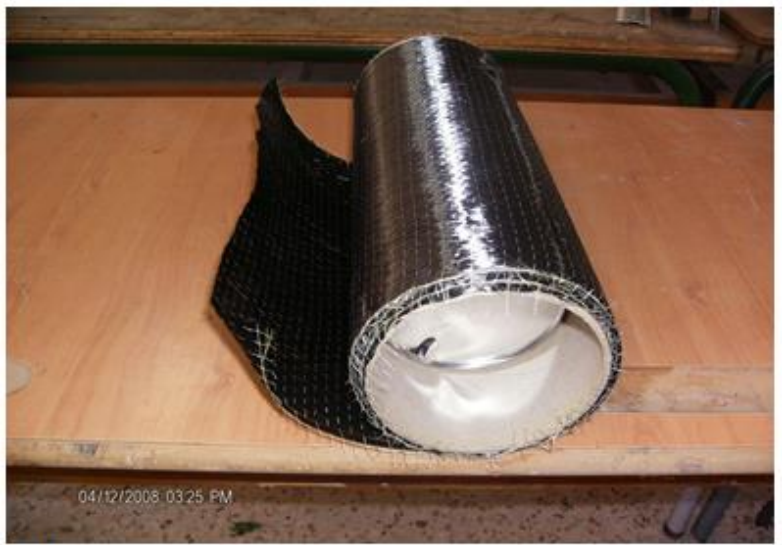

(a)

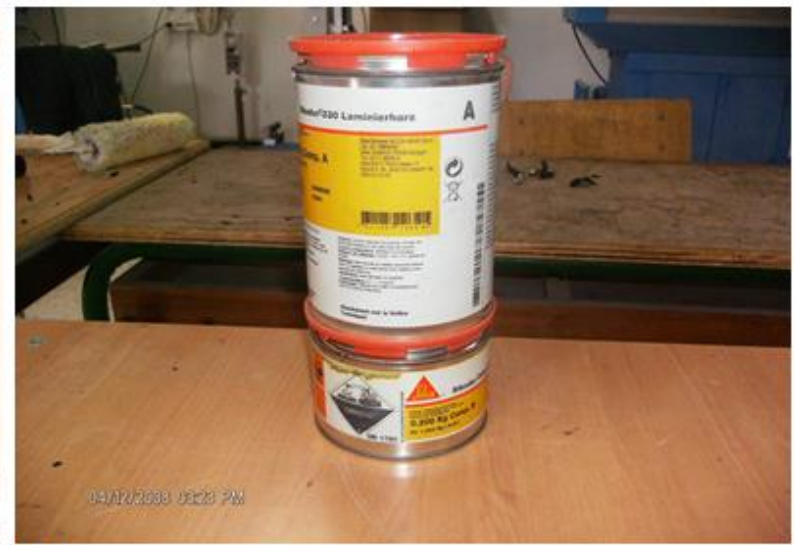

(b)

Fig 1. Materials used for reinforcement: (a) Carbon fiber reinforced polymer (CFRP), (b) Resin SIKA DUR 330.

\subsection{Specimens preparation and testing procedure}

Six (6) beams of concrete with $(15 \times 15) \mathrm{cm} 2$ of section and $75 \mathrm{~cm}$ of length were prepared, three of which were reinforced by carbon fiber fabric (CRC). Three unreinforced reference specimens were studied for comparison (URC).

After mixing concrete, the filling of prismatic molds were $15 \times 15 \mathrm{~cm} 2$ in section, with $75 \mathrm{~cm}$ length was carried out in three phases. For each phase, a vibration of the mold was carried out using a mobile stripe for $20 \mathrm{~s}$. For each series, three specimens were prepared by using the same composition. After demolding, the specimens were deposited in a water vat for 28 days. In this age the specimens underwent an operation using jacketing of carbon fiber or glass fiber.

This step consists in reinforced the specimens with carbon fiber fabrics (CFRP). Before the reinforced of specimens by composite materials, the concrete surface has been treated to remove any surface grease, laitance and any heterogeneous part. The specimen surface is then cleaned and polished with a wire brush and then dusted with an aspirator. Composite material was carefully cut to the desired dimensions. For bonding of the composite on the concrete specimen, we applied a layer of $1 \mathrm{~mm}$ of the resin on the surface and then we placed manually one (1) layer of composite material on the support.

Finally, a pressure was exerted on the composite using a roller. An example of preparation of resin and applying the composite on the support beams is shown in Figures 2 and 3 respectively.
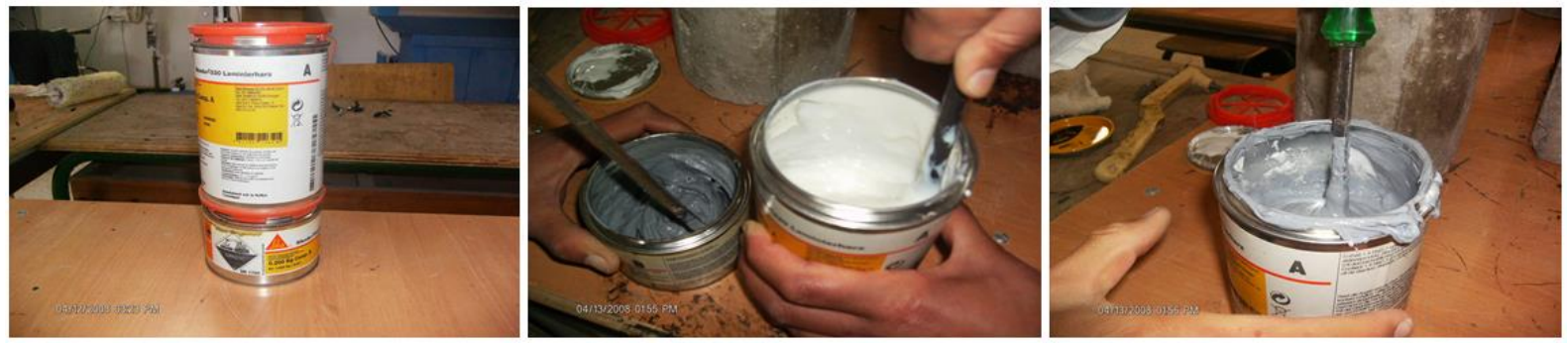

Fig 2. Preparation of resin (SIKA DUR 330).

All the prismatic specimens $(15 \times 15 \times 75) \mathrm{cm} 3$ were placed in Controlab hydraulic testing machine with the capacity of $600 \mathrm{kN}$, and subjected to three point flexural load in accordance with standard NFP 18-407 (Figures 4 and 5). 


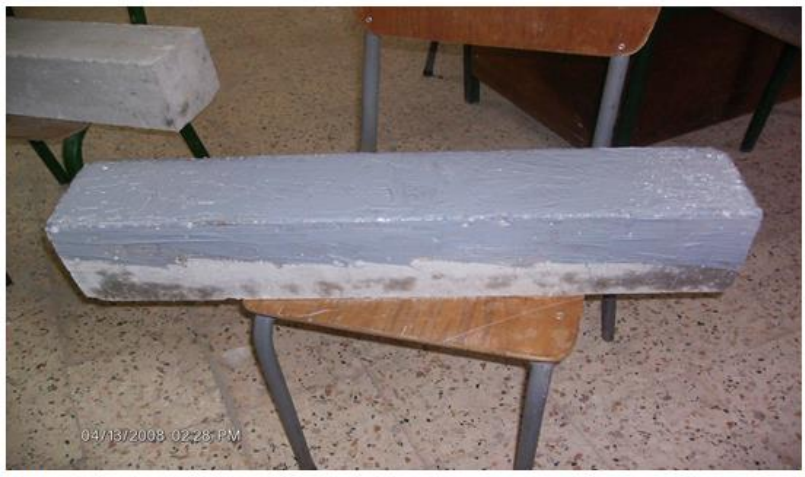

(a)

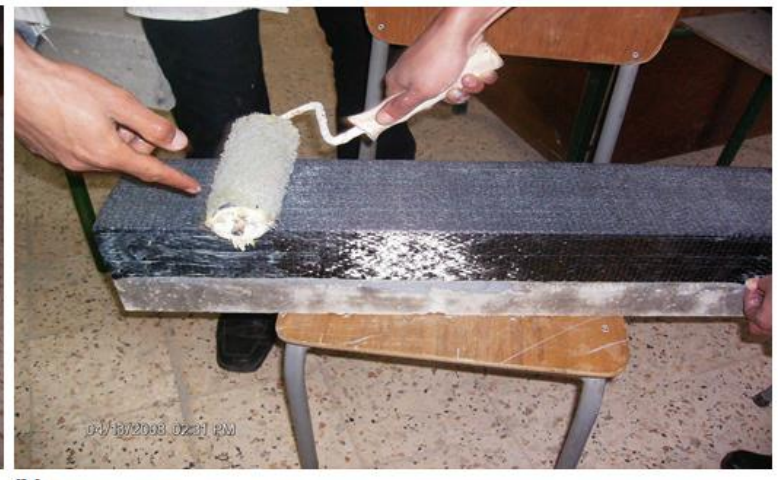

(b)

Fig 3. Reinforced of specimens by CFRP: a) Application of the resin, (b) Application of FRP.

A quasi static rate of loading is applied in the center of specimen, with a speed of $30 \mathrm{~mm} / \mathrm{mn}$. The force and the displacement are measured and recorded.

The objects of this test are, on the one hand, to quantify the contribution in specimen stiffness conferred by the composite materials considered, and on the other hand compare the beam reinforced by CFRP with unreinforced beam. The influence of composite material is observed on the failure mode and the values of resistance and displacement obtained during the crushing specimens.

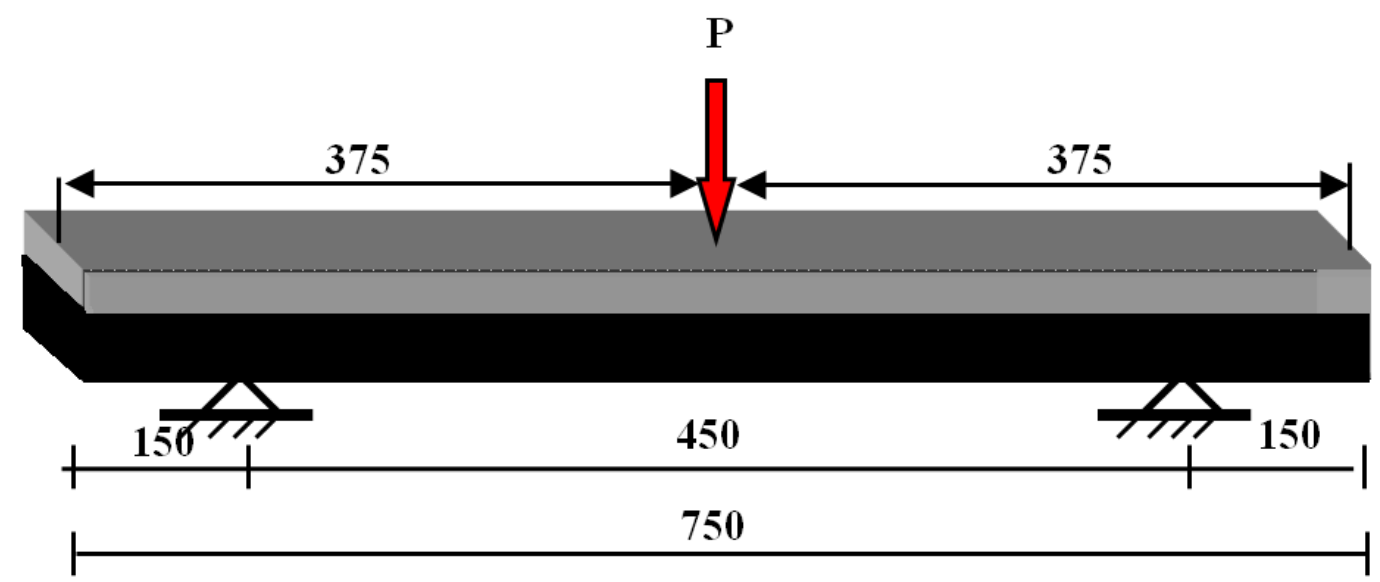

Fig 4. Three-point bending test.

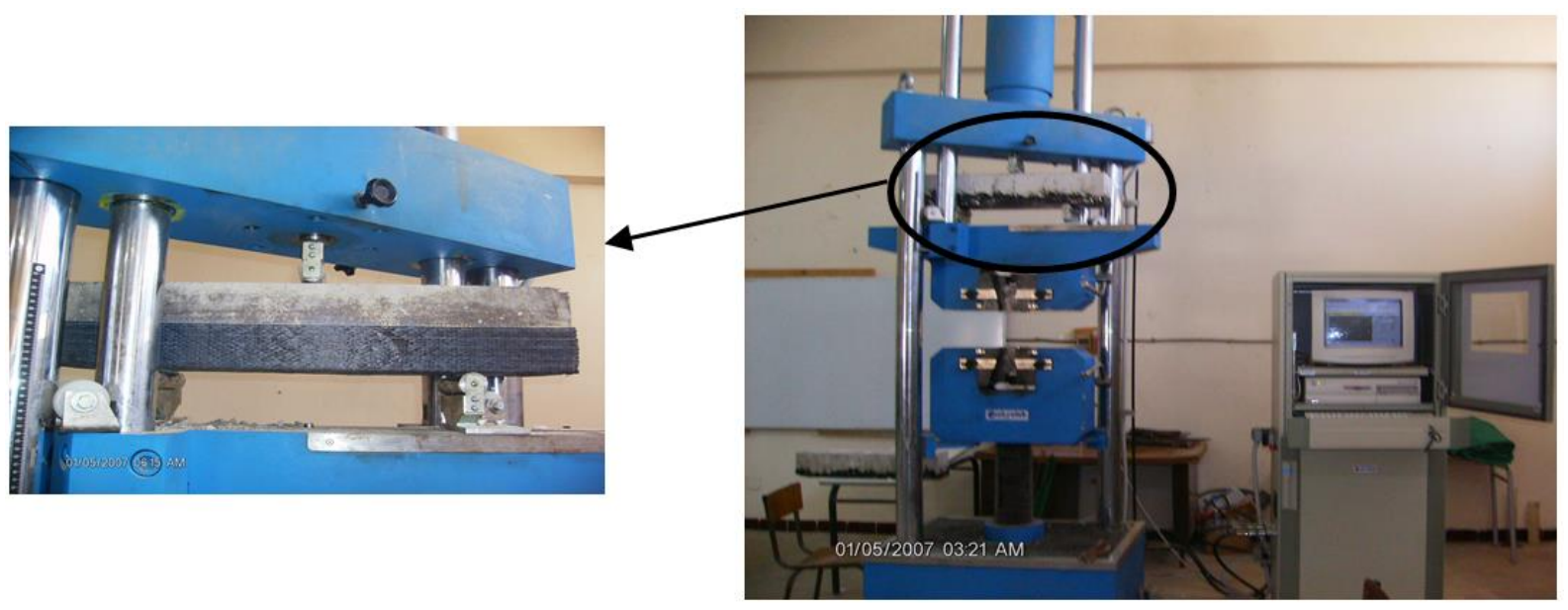

Fig 5. Loading of specimen in testing machine. 


\section{Experimental results and discussion}

The different results obtained from the flexural test, in particular, the load-displacement curves of unreinforced and reinforced concrete, are illustrated by Figure 6.

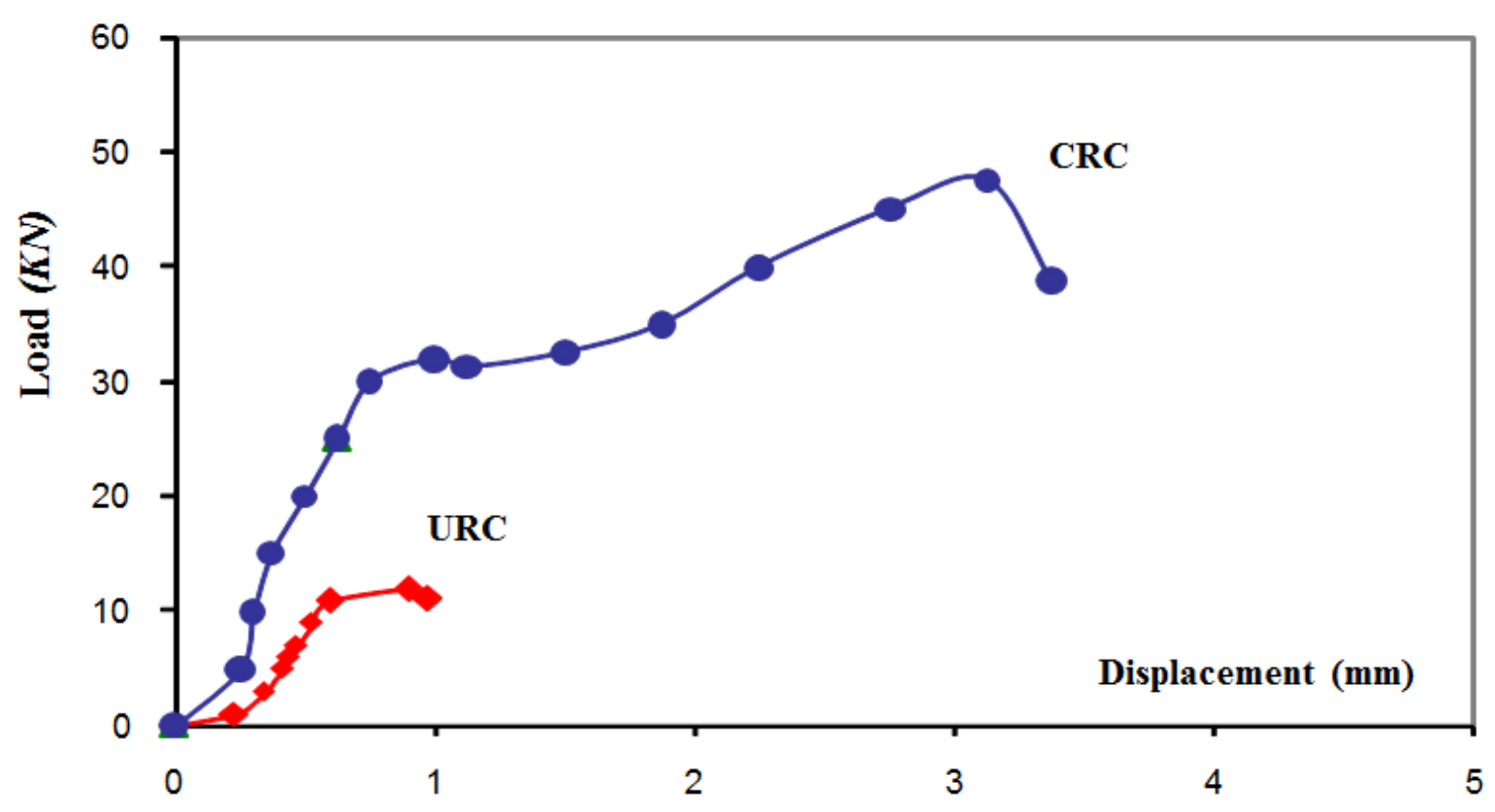

Fig 6. Load-deflection curves of reinforced concrete compared to the unreinforced concrete.

\subsection{Confinement level}

The reinforcement by composite materials can significantly increase the ultimate load and the deformation as it is shown in Figure 6. All the specimens, the ratios $\left(f_{t c} / f_{t o}\right),\left(\varepsilon_{t c} / \varepsilon_{t o}\right)$, are always significant, presenting values superior to one. For concrete beam reinforced by CFRP showed a gain in flexural strength and displacement of about $295 \%$ and $247 \%$, respectively. The composite materials offer elastic modulus and rigidity which can modify various behaviors of reinforced concrete, and improving its strength and ductility. This improvement may be due to the characteristics of fiber fabric, which has a good tensile strength and a high modulus of elasticity.

The strengthening of the composite beams in the party resisting evil has traction (tense part) aims to amend and prevent the distribution of cracks, so make a less brittle material; more ductile, it takes more energy to advance the crack. The flexural behavior laws obtained from different specimens can show that typically, all curves show an initial slope until a point of inflection, followed by a large zone of plastic deformation. Depending on the effectiveness of confinement, the stress level and the plastic zone vary considerably from one variant of confinement to another.

Table 2. Experimental test results.

\begin{tabular}{|c|c|c|c|c|c|c|c|c|}
\hline Concrete & \multicolumn{2}{l|}{$\begin{array}{l}\text { Unreinforced } \\
\text { concrete }\end{array}$} & \multicolumn{4}{l|}{ Reinforced concrete } & $\begin{array}{l}\text { Gain of } \\
\text { strength }\end{array}$ & $\begin{array}{l}\text { Gain of } \\
\text { ductility }\end{array}$ \\
\hline \hline & $\begin{array}{c}f_{t 0} \\
(\mathrm{KN})\end{array}$ & $\begin{array}{c}\varepsilon_{t o} \\
(\mathrm{~mm})\end{array}$ & $\begin{array}{c}f_{t c} \\
(\mathrm{KN})\end{array}$ & $\begin{array}{c}\varepsilon_{t c} \\
(\mathrm{~mm})\end{array}$ & $f_{t c} / f_{t 0}$ & $\varepsilon_{t c} / \varepsilon_{t o}$ & GS (\%) & GD (\%) \\
\hline URC & 12 & 0.90 & - & - & - & - & - & - \\
\hline CRC & - & - & 47.5 & 3.12 & 3.95 & 3.47 & 295 & 247 \\
\hline
\end{tabular}




\subsection{Failure mode}

The analysis of specimens broken during tensile bending test, allows us to better evaluate the contribution of strengthening the tense part of the concrete specimen by composite materials (CFRP) on his ductility and strength as well as his mastery of rupture. By viewing the openings lip cracks, the various findings can be interpreted as follows:

The unreinforced concrete (reference concrete) undergoes a classic failure of concrete loaded in bending, the failure mode observed on the concrete specimens, has a high speed of propagation of the crack that goes to loading levels then notices a sudden rupture of the specimen due to the fragility of concrete alone and its low tensile strength developed in the tension zone of the element. This failure mode is shown in Figure 7(a).

The reinforced concrete by CFRP (CRC), a formation of crack in the mid-span can be observed, and then its development parallel to the applied load will be broken by the composite.

The failure mode observed on the test specimens of concrete reinforced by CFRP, has a significant improvement on the macro-crack (Figure 7(b)). This is explained by the presence of composite in the part that does not resist tensile (stretched part) whose role is to modify and prevent the distribution of cracks, so make a material less brittle; then more ductile so it takes more energy to advance the crack. It can be also noted that both sides of the specimen are assembled. This is due to the presence of fiber fabric, which prevents the propagation of cracks, they can keep the original shape and increase the deformability of the concrete, and thus, the behavior becomes ductile instead of being fragile. This aspect of maintaining the broken pieces of concrete with the composite is very important in construction, since it is a security feature in the ruins of structures. It also allows to building elements bear additional charges even after failure. The failure is obtained by total breaking out of the composite fabric; the reinforced concrete degradation is more advanced than the control concrete.

The concrete beam reinforced with CFRP, have all been suffered a failure of carbon fabric (horizontal and vertical), and showed also a detached tissue after bear a very heavy burden that is almost four times higher than for unreinforced concrete. This is due to the characteristics of carbon fiber fabric which has good tensile strength and a high modulus of elasticity. To remedy this separation, we can improve the adhesion between the fabric and the concrete by improving the properties of the resin.

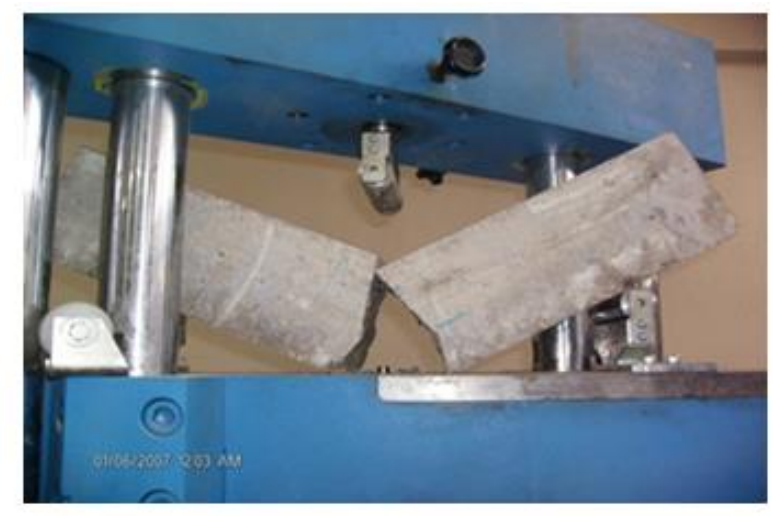

(a)

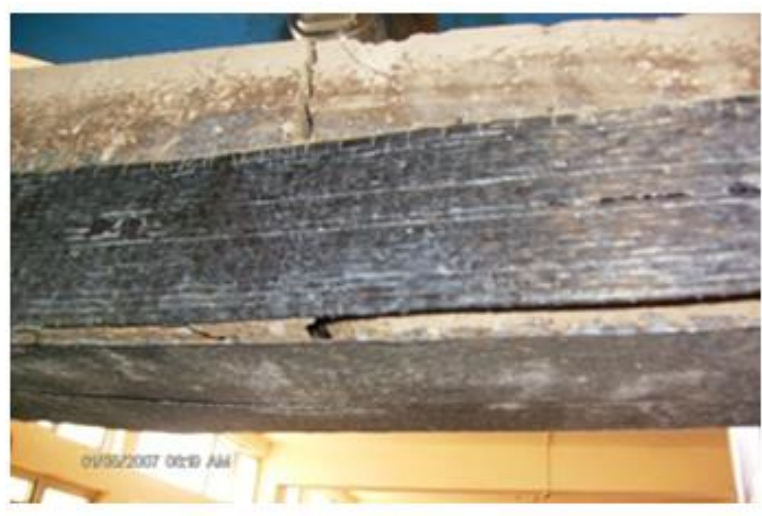

(b)

Fig 7. Failure mode of concrete: (a) URC, (b) CRC

\section{Finite element modeling of FRP reinforced concrete beams}

The finite element procedure implemented in this study is developed using the available element types from ANSYS element library. The concrete is modeled using Solid65 element type, whereas the FRP reinforcement is modeled with Solid 46 element type (Chakrabarti, 2008). By adopting and combining these two element types, the reinforced concrete beam model was 
developed. Solid65 is used for the three-dimensional modeling of solids with or without reinforcing bars. The solid is capable of cracking in tension, crushing in compression, creep nonlinearity and large deflection geometrical nonlinearity. Here, the model without reinforcing bars was used. This element has eight nodes with three degrees of freedom at each node; translations in the nodal $\mathrm{x}, \mathrm{y}$, and $\mathrm{z}$ directions.

Solid46 is a layered solid element, the element allows for up to 250 different material layers with different orientations and orthotropic material properties in each layer. The element has three degrees of freedom, namely translations in nodal $\mathrm{x}, \mathrm{y}$, and $\mathrm{z}$ directions, at each node.

Concrete is a quasi-brittle material and has different behavior in compression and tension. In compression, the stress-strain curve for concrete is linearly elastic up to about $30 \%$ of the maximum compressive strength. Above this point, the stress increases gradually up to the maximum compressive strength. Once it reaches the maximum compressive strength $f_{c o}$, the curve descends into a softening region, and eventually crushing failure occurs at an ultimate strain $f_{c u}$. In tension the stress-strain curve for concrete is approximately linearly elastic up to the maximum tensile strength. After this point, the concrete cracks and the strength decreases gradually to zero. The concrete and the FRP jacket were defined as anisotropic elastoplastic material and as an orthotropic elastic material respectively. Both solid elements were deformable. The maximum strain failure criterion was used to identify the failure of the FRP jacket. The element type used to model each material is those from the ANSYS element library and summarized in Table 3.

Table 3. Material types for modeling the beam specimens.

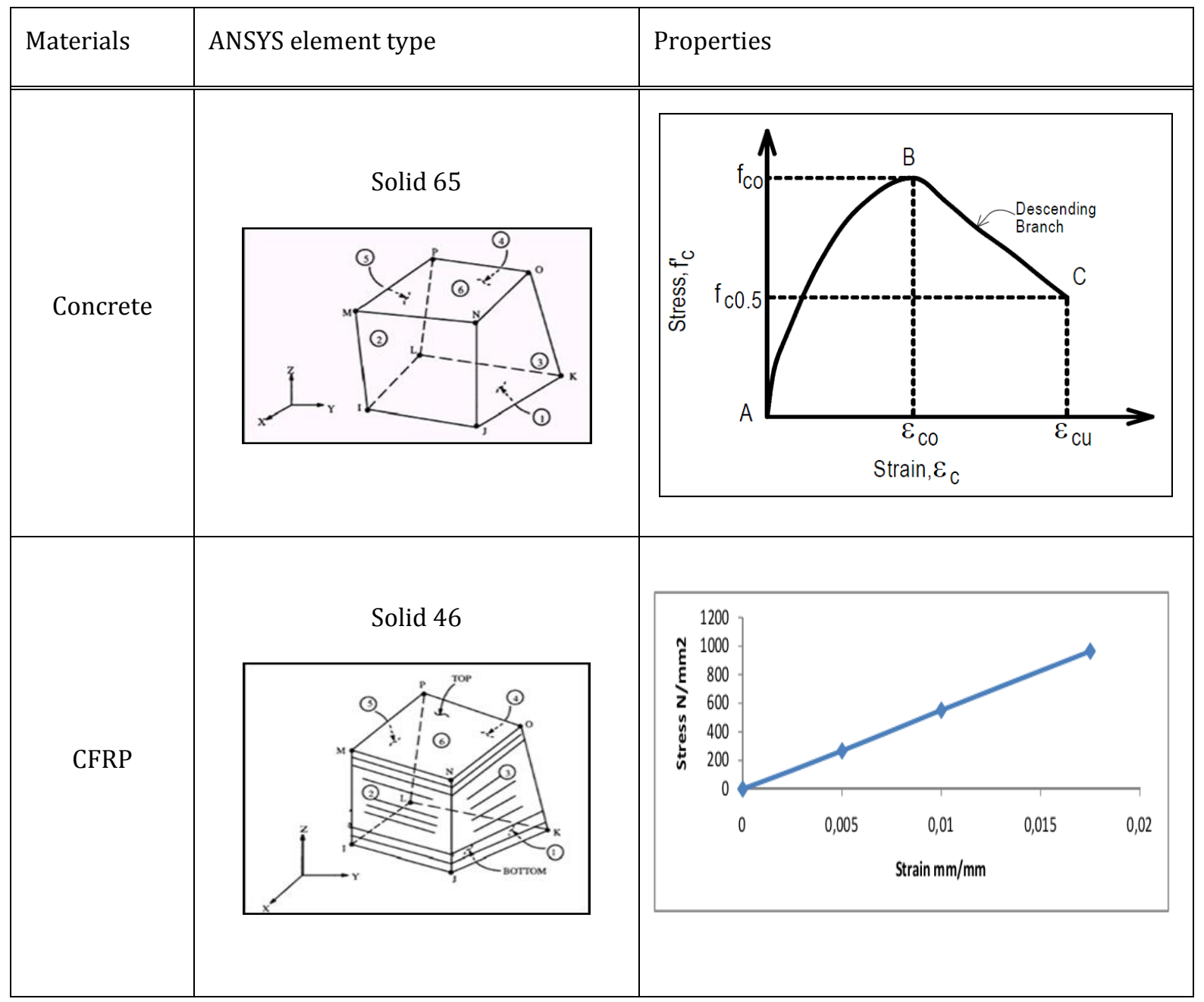




\subsection{Element meshing}

After preparing all the input data of material and geometrical properties, the beam models were divided into small elements. The meshing results of all beams specimens used for model validation are shown in Figure 8. The Solid65 and Solid46 elements are fully interconnected each other forming a single solid column model that can simulate the actual behavior of the column specimen.
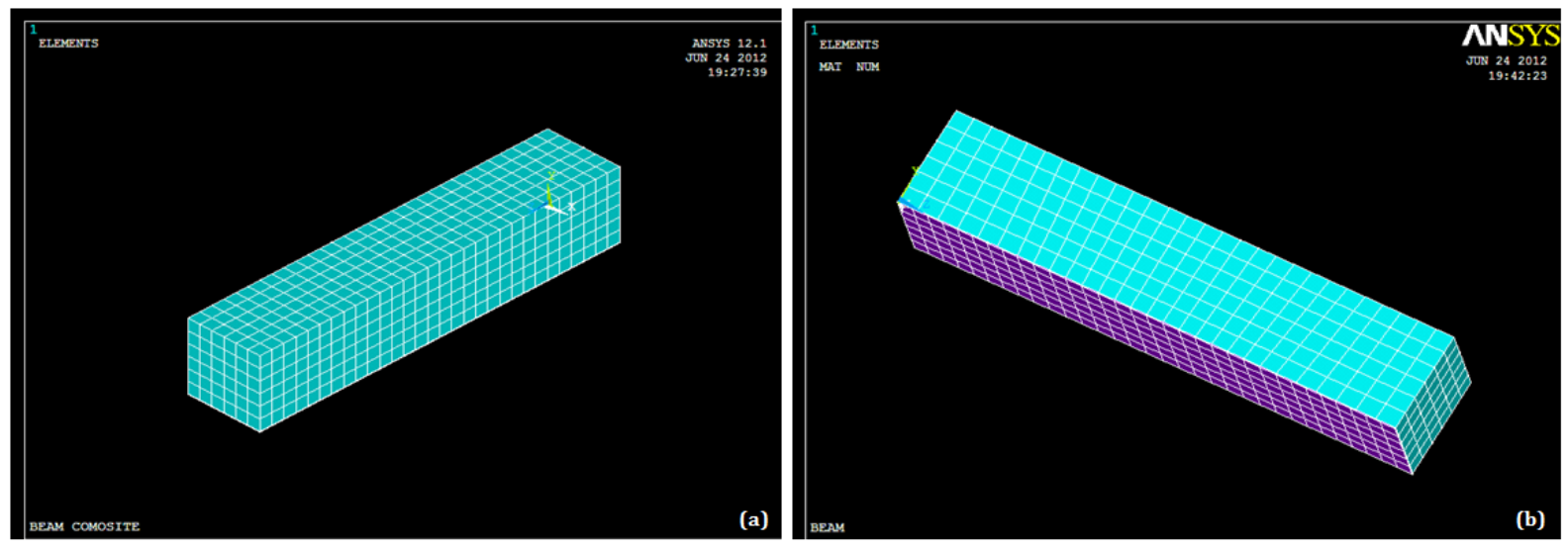

Fig 8. Element meshing of materials: (a) Concrete beam, (b) CFRP.

\subsection{Loading and boundary condition}

The beam model was subjected to flexural loading on their top face simulating the actual loading applied in the experimental tests; while the bottom side was reinforced by CFRP. The beam is tested in bending three-point (Figure 9). The model is loaded with the same conditions as the experimental test.

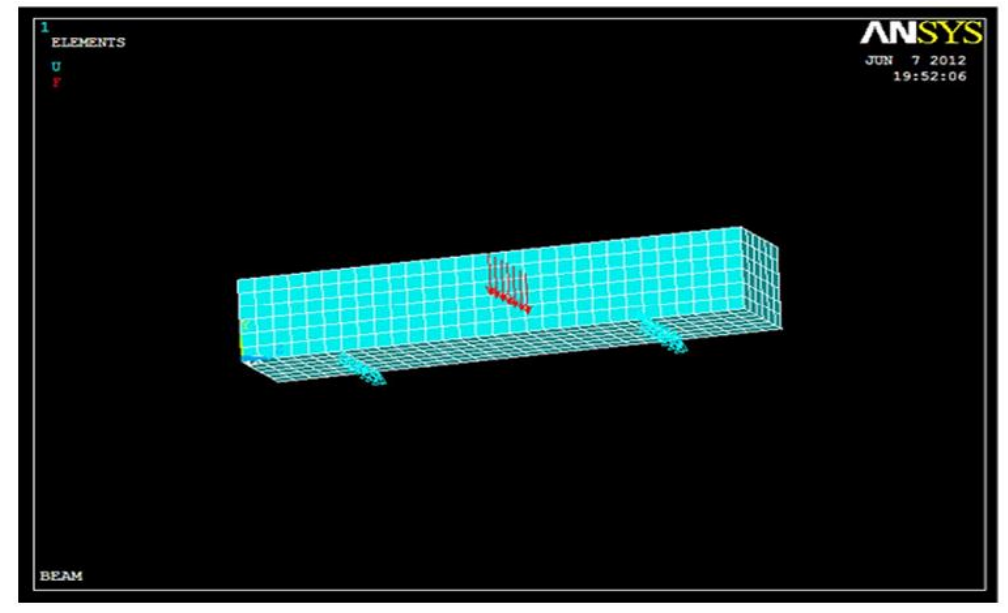

Fig 9. Loading beam model.

\subsection{Numerical results and discussions}

Figure 10, shows a comparison of the stress-displacement response of the specimens reinforced by CFRP obtained by the experiment and by the FEA. It is obvious that the FEA results are very close to the test results. This means that the FEA is validated by the test results. Hence, the FEA can be used to conduct a parametric analysis; this indicates that the actual behavior of beam specimens under flexural loading can be accurately predicted by the FEA approach. The accuracy of the proposed procedure is also confirmed by the close values of peak stress and the displacement at the peak stress obtained from the FEA and the experimental test, it can be seen that the differences of specimens reinforced by CFRP are $9.4 \%$ for the peak stress and $3.37 \%$ for the displacement. 


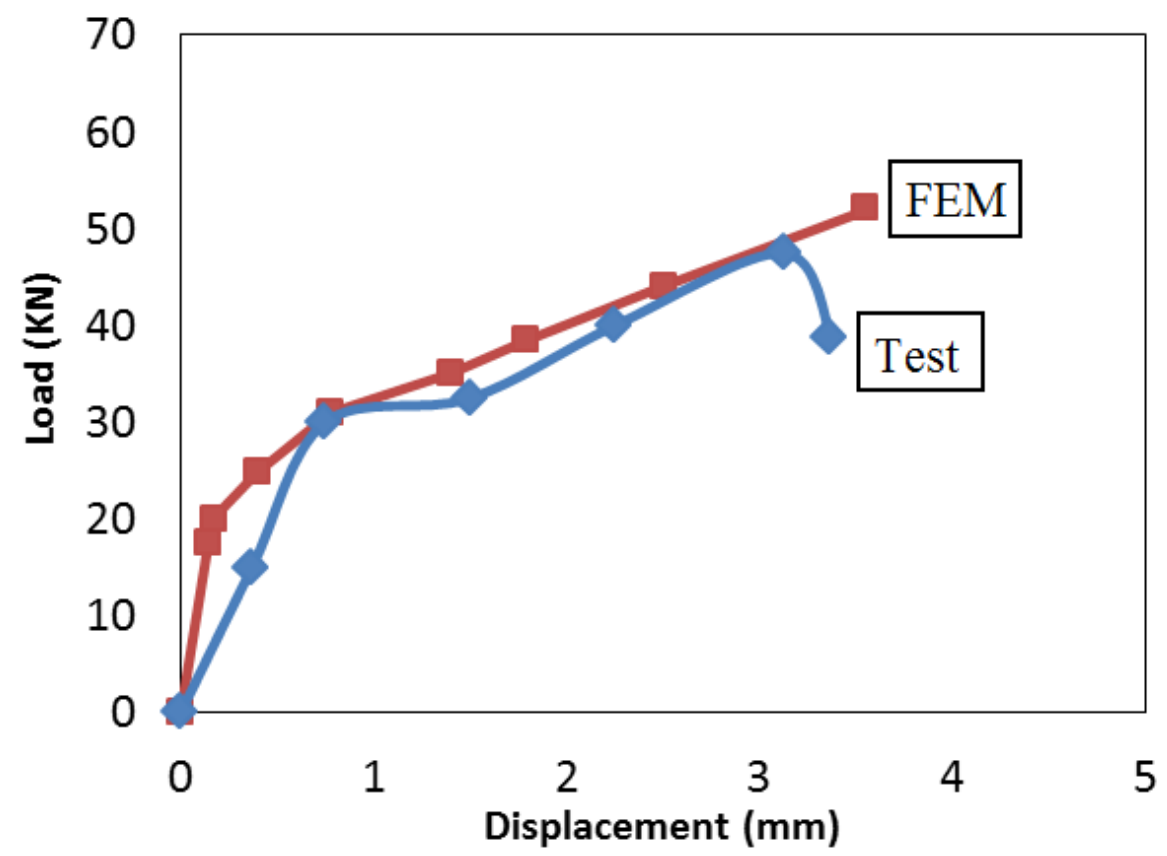

Fig 10. Load- deflection curves comparison of the FEA and test data of reinforced concrete by CFRP.

\section{Conclusions}

The behavior of concrete beams reinforced with CFRP sheets was studied by the testing and finite element analysis (FEA) outlined in this paper. The following conclusions were obtained:

- The concrete beam reinforced by CFRP showed a gain in flexural strength and displacement of about $295 \%$ and $247 \%$, respectively. The composite materials offer elastic modulus and rigidity which can modify various behaviors of reinforced concrete, and improving its strength and ductility;

- The failure mode observed on the test specimens of concrete reinforced by CFRP, has a significant improvement on prevention of macro-crack. The CFRP prevents the distribution of cracks, it can keep the original shape of beam and increase the deformability of the concrete and thus, the behavior becomes ductile instead of being fragile. The both sides of the specimen remain assembled.

- The FEA results are very close to the test results. This means that the FEA is validated by the test results. Hence, the FEA can be used to conduct a parametric analysis; this indicates that this approach is an effective method for analyzing the behavior of concrete beams strengthened with CFRP.

\section{Acknowledgement}

The authors gratefully acknowledge the generous assistance of Sika Eljazair for the supply of the composite material used in this study.

\section{List of Symbols}

$f_{\text {to }}$ : Fluxural strength of concrete.

$\varepsilon_{t o}$ : Defletion of concrete at middle of beam.

$f_{t c}:$ Flexural strength of strengthening concrete.

$\varepsilon_{t c}:$ Defletion of strengthening concrete at middle of beam. 


\section{References}

Al-Sulaimani GJ, Sharif A, Basunbul IA, Baluch MH, Ghaleb BN (1994). Shear repair of reinforced concrete by fiberglass plate bonding. ACI Struct. J., 91(4):458-64.

Ashmawi WM, Baluch MH, Azad AK (1993). Crack control design of reinforced concrete beams in flexure. ACI, Special publications, 134.

Azad AK, Baluch MH (1990). Fracture characterization of reinforced concrete, Final Report AR7-130, King Abdulaziz City for Science and Technology.

Azad AK, Mirza MS, Chan P (1989). Fracture energy of weakly reinforced concrete beams. Fatigue Fract. Eng. Mater. Struct., 12(1):9-18.

Baluch MH, Azad AK, Ashmawi W (1992). Fracture mechanics application to reinforced concrete members in flexure. Applications of fracture mechanics to reinforced concrete, 413-36.

Bosco C, Carpinteri A, Debernardi PG (1990). Minimum reinforcement in high- strength concrete. J. Struct. Eng., 116(2):427-37.

Carpenteri A. A Fracture model for reinforced concrete collapse. In: Proc. of IABSE colloquium on advanced mechanics of reinforced concrete. 1981. p. 17-30.

Chaallal O, Nollet MJ, Perraton D (1998). Shear strengthening of RC beams by externally bonded side CFRP strips. J. Compos. Constr., 2(2):111-3.

Chakrabarti A, Chandra A, Bharagava P (2008). Finite Element Analysis of Concrete Columns Confined with FRP Sheets. J. Reinf. Plast. Comp., 27(12): 1349-73.

Dreux G, Festa J (1998). Nouveau guide du béton et de ses constituants. Eyrolles, 8ème Edition, Paris, (in French).

Gerstle WH, Dey PP, Prasad NNV, Rahulkumar P, Xie M (1992). Crack growth in flexural members: A fractural mechanics approach. ACI Struct. J., 89(6): 617-25.

Ghernouti Y, Li A, Rabehi B (2012). Effectiveness of repair on damaged concrete columns by using fiberreinforced polymer composite and increasing concrete section. J. Reinf. Plast. Comp., 31(23): $1616-29$.

Malek AM, Saasatmanesh H (1998). Ultimate shear capacity of reinforced concrete beams strengthened with web-bonded fiber-reinforced plastic plates. ACI Struct. J., 95(4):391-9.

Malvar LJ, Warren GE, Inaba C (1995). Rehabilitation of navy pier beams with composite sheets. Nonmetallic (FRP) reinforcement for concrete structures. In RILEM Proceedings, Chapman \& Hall.

Salah AS, El-Adawy NM (1975). A Modified approach of estimation of the cracking moment of reinforced concrete beams. ACI(july):356-60.

Sato Y, Ueda T, Kakuta Y, Tanaka T (1996). Shear reinforcing effect of carbon fiber sheet attached to side of reinforced concrete beams. In Proceedings, of the $2^{\text {nd }}$ international conference on advanced composite materials in bridges and structures, ACMBS-II, Montreal.

Sorour MM (2004). Fracture behaviour of reinforced concrete beams under four point bending in displacement controlled environment. M.Sc. Thesis, Structural Engineering Department, Cairo University.

Sumarac D, Sekulovic M, Krajcinovic D (2003). Fracture of reinforced concrete beams subjected to three point bending. Int. J. Damage Mech., 12(1):31-44.

Triantafillou TC (1998). Shear strengthening of reinforced concrete beams using epoxy-bonded FRP composites. ACI Struct. J., 95(2):107-15.

Uji K. (1992). Improving the shear capacity of existing reinforced concrete members by applying carbon fiber sheets. T. Jpn. Concrete I., 14:253-66.

Wahab NM, Yehia NAB (2006). Fracture behavior of flanged reinforced concrete beams; Experimental investigation. In: The tenth Arab structural engineering conference.

Yannopoulos PJ (1989). Variation of concrete crack widths through the concrete cover to reinforcement. Mag. Concrete Res., 41(147):63-8. 
Yehia NAB (2003). Size effect on fracture of reinforced concrete beams: Experimental investigation. In: The ninth Arab structural engineering conference, Abu Dhabi, United Arab Emirates, November.

Yoon KML. (2000) Strengthening of concrete beams with fibre reinforced polymer (FRP) mesh. Undergraduate Thesis. Department of Civil Engineering, National University of Singapore.

Youcef SY, Amziane S, Chemrouk M (2010). Geometrical Effect on the Behavior of CFRP Confined and Unconfined Concrete Columns. J. Reinf. Plast. Comp., 29(17): 2621-35. 